\title{
Molecular Phylogeny of Asian Freshwater and Marine Stingrays Based on the DNA Nucleotide and Deduced Amino Acid Sequences of the Cytochrome $b$ Gene
}

\author{
Keijiro Sezaki, ${ }^{* 1}$ Rowshan Ara Begum, ${ }^{* 2}$ Prachit Wongrat, ${ }^{* 3}$ \\ Mansha Prasad Srivastava, ${ }^{* 4}$ Sachi SriKantha, ${ }^{* 2}$ Kiyoshi Kikuchi, ${ }^{* 2}$ \\ Hajime Ishihara, ${ }^{* 5}$ Sho Tanaka, ${ }^{* 6}$ Toru Taniuchi, ${ }^{* 7}$ and Shugo Watabe*2,*8 \\ ${ }^{* 1}$ Laboratory of Environmental Biology, Japan NUS Co. Ltd., Minato, Tokyo 108-0022, Japan \\ ${ }^{*}$ Laboratory of Aquatic Molecular Biology and Biotechnology, Graduate School of Agricultural \\ and Life Sciences, The University of Tokyo, Bunkyo, Tokyo 113-8657, Japan \\ *3Department of Fishery Biology, Faculty of Fisheries, Kasetsart University, \\ Jatujak, Bangkok 10900, Thailand \\ ${ }^{*}$ Department of Zoology, Bhagalpur University, Bhagalpur-812007, Bihar, India \\ ${ }^{*}$ Suido-sha Co. Ltd., Tama, Kawasaki 214-0038, Japan \\ *6Department of Fisheries, School of Marine Science and Technolgy, Tokai University, \\ Orido, Shimizu 424-8610, Japan \\ ${ }^{*}$ Laboratory of Fisheries Biology, Graduate School of Agricultural and Life Sciences, \\ The University of Tokyo, Bunkyo, Tokyo 113-8657, Japan
}

(Received December 16, 1998)

To elucidate the phylogenetic relationship among stingrays of three freshwater and five marine species of the genera Himantura, Dasyatis, and Pastinachus, belonging to the family Dasyatidae distributed in Thailand, Laos, India, and Japan, we determined the nucleotide sequences of the mitochondrial DNA region encoding cytochrome $b$. Using two rayfish species belonging to the superfamily Myliobatoidea as out-groups, we found three clades for the collected stingrays in the family Dasyatidae from anlayses using the neighbor-joining, maximum parsimony, and maximum likelihood algorithms. While species belonging to the genus Himantura formed one group, Dasyatis laosensis and Dasyatis sp. formed another group. The results obtained failed to show clear phylogenetic relationships of the genus Pastinachus with the genera Dasyatis and Himantura, since the corresponding bootstrap resampling values were 72,55 , and 65 in the neighbor-joining, maximum parsimony, and maximum likelihood trees, respectively.

Key words: cytochrome $b$ gene, freshwater stingray, molecular phylogeny, mitochondrial DNA

Ichthyologists studying the elasmobranchs have noted that the interrelationships at lower taxonomic levels remain confusing and controversial. ${ }^{1)}$ Recently, McEachran and Dunn ${ }^{2}$ have presented a phylogenetic analysis of skates, which reviews and summarizes the anatomical studies published over the last 45 years. However, in terms of volume of publications, phylogenetic studies that dealt with freshwater and marine stingrays are meager. Thus, their phylogenetic relationships are still under debate, though the currently available information has been evaluated recently by Lovejoy. ${ }^{3)}$

According to Nelson, ${ }^{4)}$ elasmobranchs consist of nine orders, among which all rays are grouped into one order Rajiformes, which is subdivided into four suborders. Stingrays are assembled into the superfamily Dasyatoidea, which belongs to the suborder Myliobatoidei. The superfamily Dasyatoidea is categorized by Nelson ${ }^{4}$ into two families: Dasyatidae and Urolophidae. The family Dasyatidae comprises marine, brackish, and freshwater stingrays, which are distributed in the Atlantic, Indian, and Pacific regions. This family is further subdivided into two subfamilies, Dasyatinae (stingrays) and Potamotrygoninae (river stingrays). The family Urolophidae is represented by round stingrays which live in a marine habitat and are distributed in the western Atlantic, eastern Indian, and Pacific regions. This classification is mainly based on the fossil evidence and morphological characteristics exhibited by the extinct and extant representatives of the rayfishes.

From the anaysis of mitochondrial cytochrome $b$ gene from more than 100 animal species including mammals, birds, amphibians, fishes, and some invertebrates, Kocher et al. ${ }^{5)}$ inferred that during nearly 400 million years of evolution, only about four amino acids changes have occurred in the fish lineages, and that this rate of amino acid substitution is five times slower in comparison to bird and mammal lineages. Five species of shark (Galeocerdo, Prionace, Sphyrna, Heterodontus, and Carcharhinus) were included in this comparative study. In relation to this finding,

\footnotetext{
${ }^{* 8}$ To whom all correspondence should be addressed. Tel, +81-3-5841-7520; Fax, +81-3-5841-8166; e-mail, awatabe@mail.ecc.u-tokyo.ac.jp
} 
Kitamura et al. ${ }^{6}$ reported that there was no nucleotide variation in the cytochrome $b$ gene segment ( $405 \mathrm{bp}$ ) among seven specimens of the bull shark Carcharhinus leucas collected from the Atlantic and Pacific Oceans and related river systems in Mexico and Nicaragua. Furthermore, DNA nucleotide sequences of the mitochondrial cytochrome $b$ gene have also been used by Kitamura et $a l^{\text {.) }}$ to clarify the molecular phylogeny of the sharks and rays of the superorder Squalea.

In this study, we determined the nucleotide sequences of mitochondrial DNA encoding cytochrome $b$ to elucidate the molecular phylogenetic relationships of Asian freshwater and marine stingrays belonging to the genera Dasyatis, Himantura, and Pastinachus.

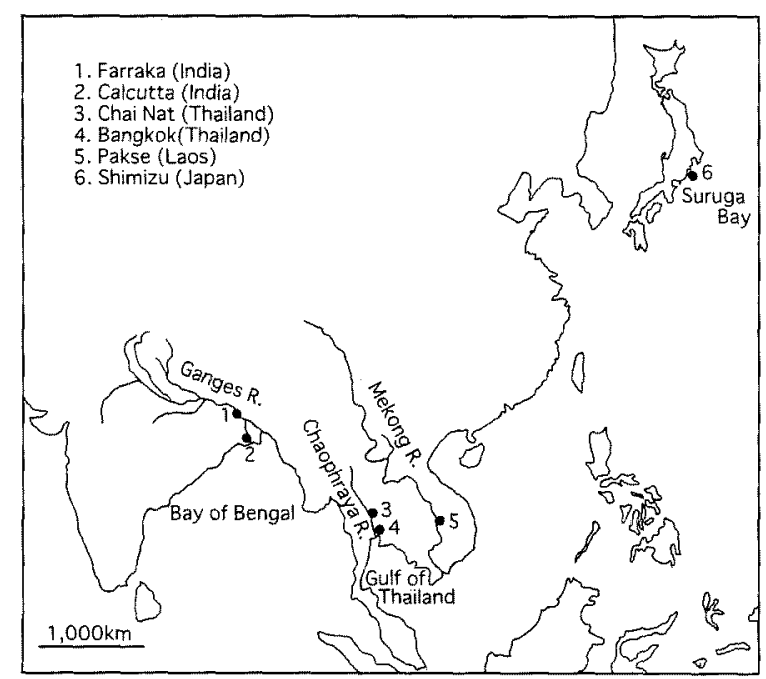

Fig. 1. A map showing sampling sites of the stingrays examined.

\section{Materials and Methods}

\section{Materials}

Nineteen sample specimens consisting of eight stingrays from Thailand, India, Laos, and Japan, and two rayfishes from Japan were examined (Fig. 1, Table 1).

Either fast skeletal muscle tissue or a segment of the skin tissue from each specimen was excised into pieces by scissors, immersed into absolute ethanol, and kept in a refrigerator before use.

\section{DNA Preparation}

The ethanol-treated muscles $(20-40 \mathrm{mg})$ were put into $500 \mu l$ of TNES $(10 \mathrm{~mm}$ Tris- $\mathrm{HCl}, \mathrm{pH} 7.5,125 \mathrm{~mm} \mathrm{NaCl}$, $10 \mathrm{mM}$ EDTA, and $0.5 \%$ SDS) containing $8 \mathrm{M}$ urea and digested with $10 \sim 15 \mu l$ of proteinase $\mathrm{K}(20 \mathrm{mg} / \mathrm{ml})$ at $37^{\circ} \mathrm{C}$ overnight." The samples were treated twice with phenol/chloroform/isoamylalcohol $(25: 24: 1, \mathrm{v} / \mathrm{v})$ and subsequently twice with chloroform/isoamylalcohol $(24: 1, v / v)$. To the aqueous layer containing DNA was added $50 \mu l$ of $3 \mathrm{M}$ sodium acetate $(\mathrm{pH} 5.2)$ and $1 \mathrm{ml}$ of $99.5 \%$ ethanol. DNA pelleted by centrifugation at $16,000 \times g$ for $15 \mathrm{~min}$ was washed with $70 \%$ ethanol, dried under vacuum, and dissolved in $500 \mu l$ of TE buffer (10 mM Tris- $\mathrm{HCl}, \mathrm{pH} 7.5,1 \mathrm{~mm}$ EDTA).

\section{DNA Amplification}

DNA fragments encoding the mitochondrial cytochrome $b$ gene were amplified by PCRs. Amplifying conditions were $93^{\circ} \mathrm{C}$ for $60 \mathrm{~s}$ in denaturation, $53^{\circ} \mathrm{C}$ for $90 \mathrm{~s}$ in annealing, and $72^{\circ} \mathrm{C}$ for $90 \mathrm{~s}$ in extension for 30 cycles, with a final polymerization step at $72^{\circ} \mathrm{C}$ for five min. PCR products were resolved by electrophoresis in a $1.5 \%$ agarose gel of a low melting point grade and stained with ethidium bromide to visualize DNA bands. The separated bands were excised from the gel and placed into 500

Table 1. Localities and habitats of Asian stingrays and ray fishes analyzed for the cytochrome $b$ gene

\begin{tabular}{|c|c|c|c|c|}
\hline Samples & Scientific name & Locality $^{* 1}$ & Country & Habitat \\
\hline 1 & Himantura signifer & Chaophraya R. (3)*2 & Thailand & Freshwater \\
\hline 2 & Himantura signifer & Chaophraya R. (3) & Thailand & Freshwater \\
\hline 3 & Himantura signifer & Chaophraya R. (3) & Thailand & Freshwater \\
\hline 4 & Himantura signifer & Chaophraya R. (3) & Thailand & Freshwater \\
\hline 5 & Himantura chaophraya & Chaophraya R. (3) & Thailand & Freshwater \\
\hline 6 & Himantura chaophraya & Chaophraya R. (3) & Thailand & Freshwater \\
\hline 7 & Himantura chaophraya & Ganges R. (1) & India & Freshwater \\
\hline 8 & Himantura imbricata & Gulf of Thailand (4) & Thailand & Marine \\
\hline 9 & Himantura imbricata & Gulf of Thailand (4) & Thailand & Marine \\
\hline 10 & Himantura imbricata & Gulf of Thailand (4) & Thailand & Marine \\
\hline 11 & Himantura gerrardii & Bay of Bengal (2) & India & Marine \\
\hline 12 & Pasitinachus sephen & Chaophraya R. (3) & Thailand & Freshwater/Marine \\
\hline 13 & Pasitinachus sephen & Chaophraya R. (3) & Thailand & Freshwater/Marine \\
\hline 14 & Pasitinachus sephen & Ganges R. (1) & India & Freshwater/Marine \\
\hline 15 & Dasyatis laosensis & Mekong R. (5) & Laos & Freshwater \\
\hline 16 & Dasyatis laosensis & Mekong R. (5) & Laos & Freshwater \\
\hline 17 & Dasyatis sp. & Gulf of Thailand (4) & Thailand & Marine \\
\hline 18 & Dasyatis sp. & Gulf of Thailand (4) & Thailand & Marine \\
\hline 19 & Dasyatis akajei & Suruga Bay (6) & Japan & Marine \\
\hline 20 & Aetobatus narinari & Suruga Bay (6) & Japan & Marine \\
\hline 21 & Gymunura japonica & Suruga Bay (6) & Japan & Marine \\
\hline
\end{tabular}

*1 $\mathrm{R}$ denotes river.

$*_{2}$ Numbers in the parenthses represent sampling locations shown in Fig. 1 . 


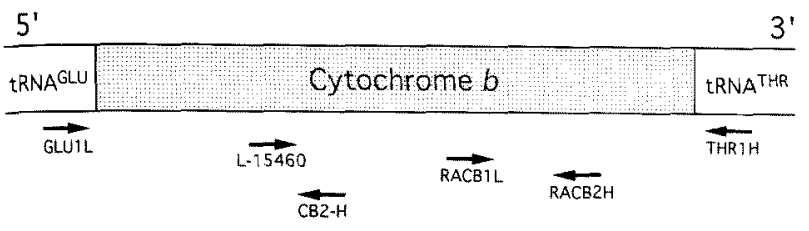

Fig. 2. A schematic diagram of an amplified region of stingray mitochondrial DNA and sites of oligonucleotides (arrows) used as primers for PCR and DNA sequencing.

$\mu l$ of TE buffer. The gel bands containing DNA were incubated at $65^{\circ} \mathrm{C}$ for $20 \mathrm{~min}$ and DNA was extracted by the phenol/chloroform method as described before. Initial amplifications of DNA fragments encoding the full length of cytochrome $b$ employed versatile primers, GLU1L $\left(5^{\prime} \mathrm{CACCGTTGTTATTCAACTAC} 3^{\prime}\right)$ for the light strand and THR1H (5'GGATTACAAGACCGATGCTT3') for the heavy strand, which were originally synthesized in this study by reference to the homologous sequences of carp, lungfish, amphibia, and human (Fig. 2). Later, we designed two new primers RACB1L (5'AACTTTATCCCAGCTAACCC3') and RACB2H (5'GAAGGTAAGGCTTCGTTGTT3') for the light and heavy strands of the cytochrome $b$ gene, respectively, in addition to the published primers L-15460 (5'ACAGCCTTCGTAGGTTATGTACT3') and CB2-H $\left(5^{\prime}\right.$ CCCTCAGAATGATATTTGTCCTCA $\left.^{\prime}\right){ }^{8}{ }^{8}$

DNA nucleotide sequences were determined for both strands with a Perkin Elmer Applied Biosystems model 373S DNA sequencer after labeling samples with Taq Dye Deoxy terminator cycle sequencing kits.

\section{Phylogenetic Analysis}

The alignments for DNA nucleotide and deduced amino acid sequences were carried out by package software SeqEd (Perkin Elmer). The neighbor-joining, ") maximum parsimony, ${ }^{10)}$ and maximum likelihood ${ }^{11)}$ methods were employed throughout for phylogenetic tree constructions and presentation of the results. The neighbor-joining analysis was performed with PHYLIP, using Kinuma's two parameters genetic distance modified by Felsenstein. ${ }^{12)}$ The maximum parsimony analysis was carried out with MacClade ${ }^{13)}$ and PAUP, ${ }^{14)}$ using heuristic search. The maximum likelihood analysis was performed with DNAML in PHYLIP. ${ }^{12)}$

\section{Results}

\section{Sample Collection}

Himantura signifer, $H$. chaophraya, and Dasyatis laosensis are identified as obligatory freshwater stingrays. ${ }^{15)}$ While specimens of Pastinachus sephen were collected from the Chaophraya and Ganges Rivers (Fig. 1), this species inhabits both freshwater and marine environments. ${ }^{15)}$ Other stingray species in Table 1 belong to the marine habitat: $H$. imbricata and Dasyatis sp. (unidentified) collected from the Gulf of Thailand off Bangkok, and $H$. gerrardii collected from the Bay of Bengal off Calcutta. Two marine stingray species, eagle ray Aetobatus narinari and butterfly ray Gymunura japonica, which belong to the superfamily Myliobatoidea, were collected from Suruga
Bay off Shimizu in Japan and used as out-groups in this study. All the samples were collected in 1996 and 1997.

\section{DNA Nucleotide and Deduced Amino Acid Sequences of Cytochrome b}

DNA fragments encoding the full length of cytochrome $b$ were amplified by PCR and sequenced using $5^{\prime}-$ and $3^{\prime}$ primers designed in the present study or previously reported. ${ }^{7,8)}$ The region amplified for most species examined contained 1,143 nucleotides including the stop codon TAA and encoded 380 amino acids. $G$. japonica exceptionally contained 1,149 nucleotides encoding 382 amino acid residues, six nucleotides being inserted upstream the stop codon. Consequently, nucleotides from 1,141 to 1,146 (381-382th amino acid residues) of this species were omitted from the data analysis. With such arrangements for the DNA nucleotide sequence analysis, there were 402 variable sites (data not shown), whereas in the sequences of $\mathbf{3 8 0}$ amino acids, 88 variable sites were observed (Fig. 3).

\section{Intraspecies Variations in Nucleotide and Amino Acid Sequences}

Pairwise distances of nucleotide and amino acid sequences between the 12 taxa calculated by PAUP ${ }^{11)}$ are shown in Table 2 . Intraspecies variations were observed between samples geographically isolated for two freshwater species, $H$. chaophraya and $P$. sephen. One specimen of $H$. chaophraya from the Ganges River showed variations in 23 nucleotides and five amino acids from the two specimens from the Chaophraya River. One specimen of $P$. sephen from the Ganges River also showed differences in 91 nucleotides and seven amino acids from that of the $P$. sephen specimen collected from the Chaophraya River. On the other hand, only one nucleotide substitution was observed among the three specimens of $H$. imbricata from the Gulf of Thailand. No genetic variation was observed among the specimens of $H$. signifer, D. laosensis, and Dasyatis sp. examined. Intraspecific variations described above for $H$. chaophraya and $P$. sephen were large enough to be reminiscent of those in different species. Therefore, phylogenic analyses were performed on 12 taxa including ten species and two geographically isolated races of $H$. chaophraya and $P$. sephen as shown in Table 2.

\section{Ratio of Transition to Transversion}

Both transition and transversion substitutions increased linearly with increasing genetic distance until around 0.2 (Fig. 4). The average value was calculated to be 4.1 for pairwise ratio of each taxa. Therefore, the value of 8.2 was used for weighing transversion to transition in the following phylogenetic analyses.

\section{Phylogenetic Trees of Cytochrome b Gene}

Three phylogenetic trees based on DNA nucleotide sequences by the neighbor joining, maximum parsimony, maximum likelihood methods, were obtained for 12 taxa, where two rayfishes collected in Japan were included in order to root the trees (Fig. 5). The following inferences were obtained from all the trees obtained. First, stingrays belonging to the genus Himantura formed one group, where the first freshwater stingray species $H$. signifer collected in Thailand branched with two marine stingray spe- 


\begin{tabular}{|c|}
\hline $\begin{array}{l}\text { H.signifer } \\
\text { H.chaophraya (T) } \\
\text { H.chaophraya(I) } \\
\text { H.imbricata } \\
\text { H.gerrardi } \\
\text { D.sephen(T) } \\
\text { P.sephen(I) } \\
\text { D.laosensis } \\
\text { D.species } \\
\text { D.akajei } \\
\text { A.narinari } \\
\text { G.japonica }\end{array}$ \\
\hline $\begin{array}{l}\text { H. signifer } \\
\text { H. chaophraya (T) } \\
\text { H. chaophraya }(I) \\
\text { H.imbricata } \\
\text { H. gerrardi } \\
\text { P. sephen (T) } \\
\text { P.sephen (I) } \\
\text { D.laosensis } \\
\text { D.species } \\
\text { D.akajei } \\
\text { A.narinari } \\
\text { G.japonica }\end{array}$ \\
\hline $\begin{array}{l}\text { H. signifer } \\
\text { H. chaophraya }(\mathrm{T}) \\
\text { H.chaophraya }(\mathrm{I}) \\
\text { H.imbricata } \\
\text { H.gerrardi } \\
\text { P.sephen (T) } \\
\text { P.sephen (I) } \\
\text { D.laosensis } \\
\text { D.species } \\
\text { D.akajei } \\
\text { A.narinari } \\
\text { G.japonica }\end{array}$ \\
\hline $\begin{array}{l}\text { H. signifer } \\
\text { H. chaophraya(T) } \\
\text { H. chaophraya(I) } \\
\text { H.imbricata } \\
\text { H.gerrardi } \\
\text { P. sephen (T) } \\
\text { P.sephen (I) } \\
\text { D. laosensis } \\
\text { D.species } \\
\text { D.akajei } \\
\text { A.narinari } \\
\text { G.japonica }\end{array}$ \\
\hline $\begin{array}{l}\text { H. signifer } \\
\text { H. chaophraya (T) } \\
\text { H. chaophraya(I) } \\
\text { H.imbricata } \\
\text { H.gerrardi } \\
\text { P. sephen (T) } \\
\text { P. sephen (I) } \\
\text { D. Iaosensis } \\
\text { D.species } \\
\text { D.akajei } \\
\text { A.narinari } \\
\text { G.japonica }\end{array}$ \\
\hline $\begin{array}{l}\text { H. signifer } \\
\text { H. chaophraya (T) } \\
\text { H. chaophraya(I) } \\
\text { H.imbricata } \\
\text { H.gerrardii } \\
\text { P. sephen(T) } \\
\text { P.sephen(I) } \\
\text { D.laosensis } \\
\text { D.species } \\
\text { D.akajei } \\
\text { A.narinari } \\
\text { G.japonica }\end{array}$ \\
\hline
\end{tabular}

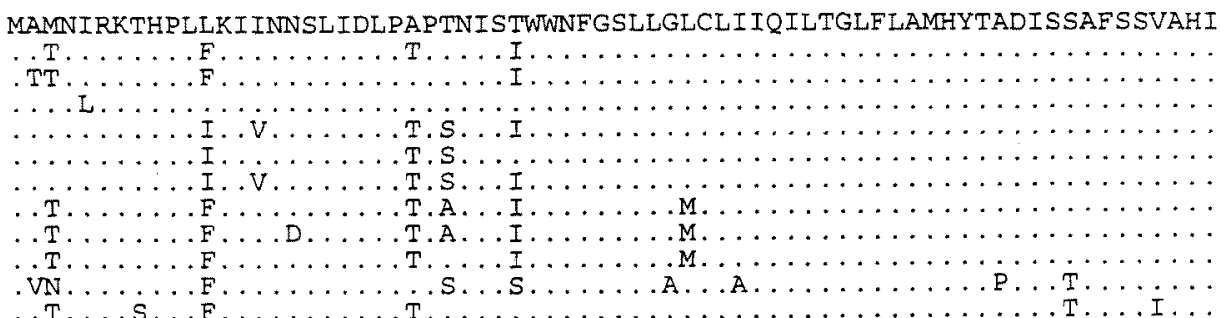

CRDVNYGWLIRNTHANGASLF FICAYLHIARGFYYGSYLYKEAWNIGVIILVLLMATAFVGYVLPWGQMS 140

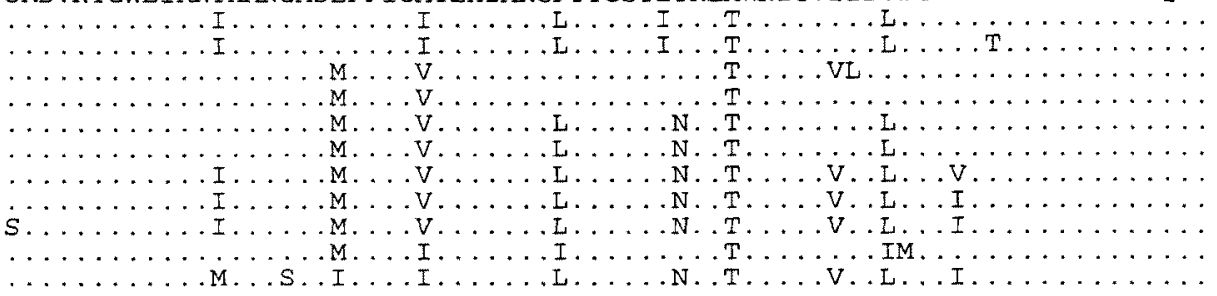

FWGATVITNLLSALPYIGDMLVQWIWGGF SVDNATLTRFFAFHFLLPFIIAALTMVHLLFLHETGSNNPI 210

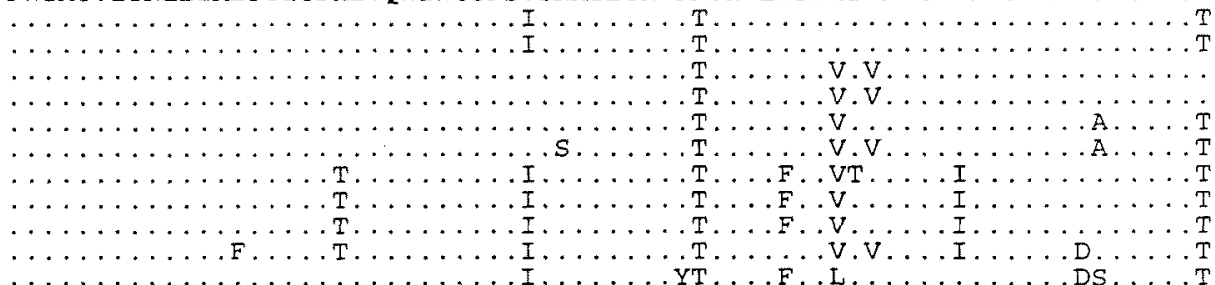

GLDSNMDKIPFHPYYSYKDLLGFFILLLILTLLTLFLPNLLGDAENFIPANPLVTPPHIKPEWYFLFAYA 280

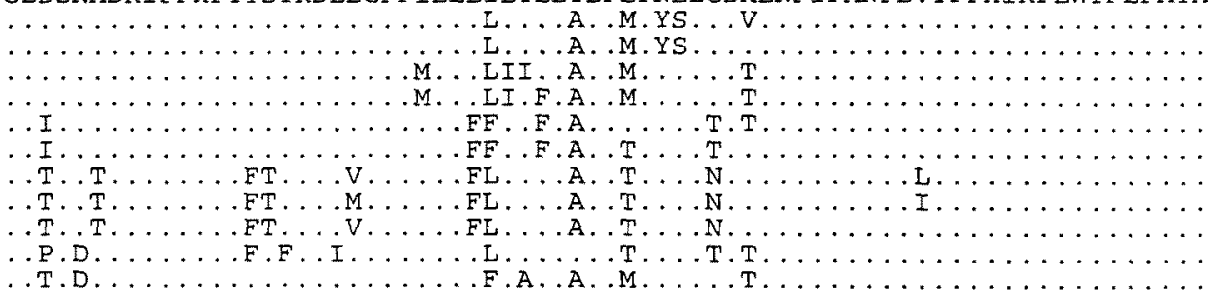

ILRSI PNKLGGVLALAFSILILLLVPLLHTSKQRSLTFRPITQTLFWLLIVNTIILTWIGGQPVEQPFIT 350

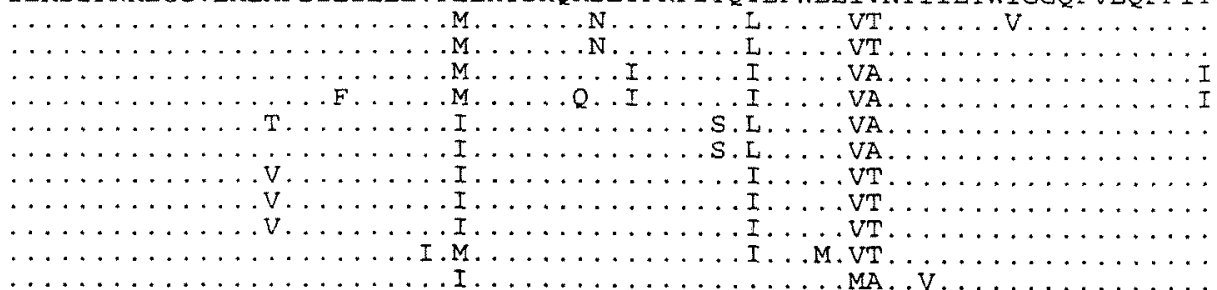

IGQIASITYFSFFIILFPIAGWWENKMLNL

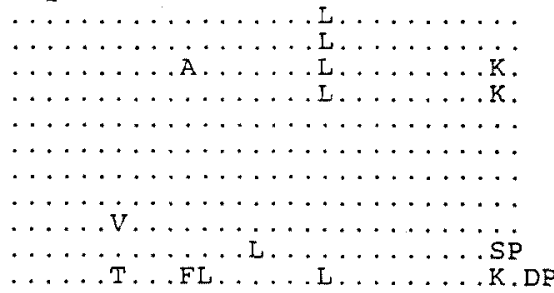

Fig. 3. Amino acid sequences of the full length of cytochrome $b$ in stingrays and rayfishes.

Dots indicate residues matching with those of Himantura signifier. The letters " $T$ " and " $\mathrm{I}$ " in parentheses added to $H$. chaophraya and $P$. sephen indicate Thailand and India, respectively, where samples were collected. The nucleotide sequence data for deducing the present amino acid sequences will appear in the DDBJ/EMBL/GenBank nucleotide sequence databases with the accession numbers AB021494-AB021505. 
Table 2. Nucleotide substitutions and amino acid replacements between taxa which are calculated with PAUP

\begin{tabular}{|c|c|c|c|c|c|c|c|c|c|c|c|c|}
\hline & & $\begin{array}{c}1 \\
\text { H. signifer }\end{array}$ & $\frac{2}{H . \text { chaophraya (T) }}$ & H. chaophraya (I) & H. imbricata & H. gerrardii & $\begin{array}{c}6 \\
\text { P. sephen (T) }\end{array}$ & $\begin{array}{c}7 \\
\text { P. sephen (1) }\end{array}$ & $\stackrel{8}{\text { D. laosensis }}$ & $\begin{array}{c}9 \\
\text { D. species }\end{array}$ & $\begin{array}{l}10 \\
\text { D. akajei }\end{array}$ & A. narinari \\
\hline 1 & H. signifer & - & & & & & & & & & & \\
\hline 2 & H. chaophraya $(\mathrm{T})^{* 1}$ & $181(26)^{* 3}$ & - & & & & & & & & & \\
\hline 3 & H. chaophraya $(\mathrm{l})^{* !}$ & $176(25)$ & $23(5)$ & - & & & & & & & & \\
\hline 4 & H. imbricata & $146(25)$ & $171(31)$ & $169(31)$ & - & & & & & & & \\
\hline 5 & H. gerrardii & $166(28)$ & $176(29)$ & $177(31)$ & $67(13)$ & - & & & & & & \\
\hline 6 & $P$. sephen $(\mathrm{T})$ & $207(26)$ & $196(28)$ & $194(30)$ & $193(30)$ & $174(25)$ & -- & & & & & \\
\hline 7 & $P$. sephen (I) & $193(29)$ & $188(29)$ & $188(30)$ & $181(32)$ & $137(23)$ & $91(7)$ & - & & & & \\
\hline 8 & D. Loosensis & 203(39) & $188(3 i)$ & $191(32)$ & $198(41)$ & $186(40)$ & $172(29)$ & $160(29)$ & - & & & \\
\hline 9 & D.species ${ }^{* 2}$ & $204(39)$ & $181(31)$ & $192(32)$ & $197(41)$ & $182(40)$ & $174(29)$ & $163(29)$ & $27(5)$ & - & & \\
\hline 10 & D. akajei & $205(38)$ & $184(30)$ & $185(31)$ & $200(40)$ & $193(40)$ & $177(29)$ & $167(29)$ & $37(6)$ & $45(6)$ & - & \\
\hline 11 & A. narinari & $245(42)$ & $238(41)$ & $239(40)$ & $227(43)$ & $214(42)$ & $216(41)$ & $218(41)$ & $206(42)$ & $208(42)$ & $208(42)$ & - \\
\hline 12 & G. japonica & $253(40)$ & $233(34)$ & $238(36)$ & $217(39)$ & $218(43)$ & $224(35)$ & $223(39)$ & $214(40)$ & $214(39)$ & $216(37)$ & $215(50)$ \\
\hline
\end{tabular}

$*_{1} T$ and $I$ in the parentheses represent Thailand and India, respectively.

*z Species unidentified

*3 Numbers in the parentheses represent the replacements of amino acid.

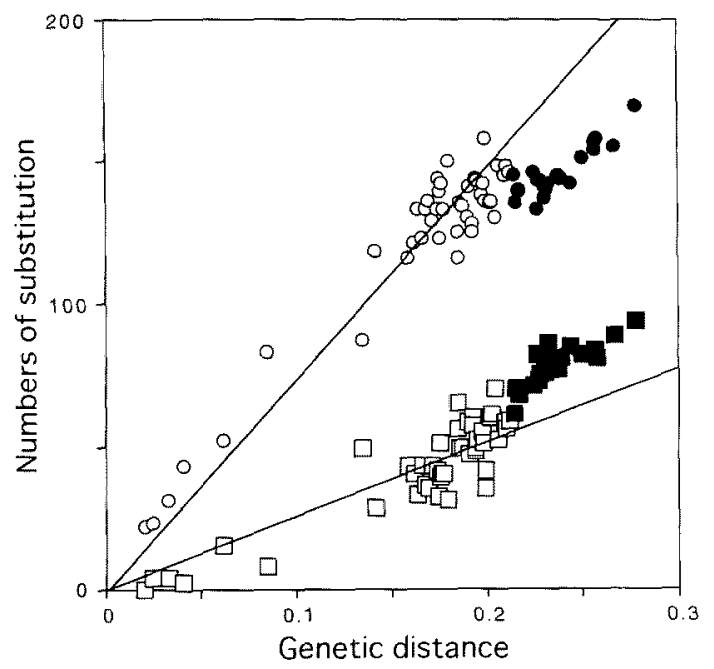

Fig. 4. Relationship of transition and transversion substitutions to Kimura's two parameters genetic distance modified by Felsenstein. ${ }^{12}$ The open circles and squares represent transition and transversion in the eight species of stingrays, respectively, whereas solid circles and squares represent substitution in 21 pairwise with the out-group species.

cies $H$. imbricata collected in Thailand and $H$. gerrardii collected in India, differing from two samples of the second freshwater stingray $H$. chaophraya collected in Thailand and India. However, the present two taxa of $H$. chaophraya yielded two separable lineages, suggesting the occurrence of different local races in this species. Secondly, the third freshwater stingray of $D$. laosensis, collected in Laos, a marine stingray of Dasyatis sp. collected in Thailand, and D. akajei collected in Japan, formed the same group. Thirdly, two local races were demonstrated for $P$. sephen. These relationships were well supported with high values in bootstrap analysis.

Although $D$. Laosensis, the marine stingray of Dasyatis sp., and $P$. sephen formed the same group in the maximum parsimony and maximum likelihood trees, their respective bootstrap values, 55 and 65 , were slightly low. On the other hand, D. akajei, D. laosensis and Dasyatis $\mathrm{sp}$. were in the same group and these branched off from other stingrays including the Pastinachus species in the neighbor-joining tree. The relationship within species belonging to the genus Himantura was the same irrespective of the phylogenetic trees constructed. In contrast to the maximum parsimony and maximum likelihood trees, however, the neighbor-joining tree provided a close relationship for the genus Pastinachus to that of the genus Himantura than to the genus Dasyatis, although their bootstrap value was not high.

\section{Phylogenetic Trees with Amino Acid Sequences of Cytochrome b}

The phylogenetic trees derived from the amino acid sequences of cytochrome $b$ according to the neighbor-joining and maximum parsimony methods are shown in Fig. 6. These appear to be slightly different from those based on nucleotide sequences. Species belonging to the genera Himantura, Dasyatis and Pastinachus were in the distinct groups according to the data based on amino acid sequences, although their phylogenetic relationship was not well established.

The most remarkable difference between the phylogenetic trees with amino acid sequences and DNA nucleotide sequences was the placement of the marine rayfish $A$. narinari collected in Japan to an inner group, although this placement seems to be less reliable. The phylogenetic tree according to the maximum parsimony method indicated that the present out-groups might not be best.

\section{Discussion}

Nelson ${ }^{4)}$ has recorded that the subfamily Dasyatidae (stingrays) consists of six genera, with about 50 species. In this study, our attention was focused on three genera (namely Himantura, Dasyatis, and Pastinachus) of Asian stingrays. We analyzed eight species belonging to these three genera, among which $H$. signifer ${ }^{16)}$ and $D$. laosensis $^{17)}$ and $H$. chaophraya ${ }^{18)}$ were reported as new species in 1982,1987 , and 1990 , respectively.

The molecular phylogenetic analyses by the neighborjoining, maximum parsimony and maximum likelihood methods based on DNA nucleotide sequences of the cytochrome $b$ gene showed that the general topology of the trees remained mostly unaltered. The DNA nucleotide 

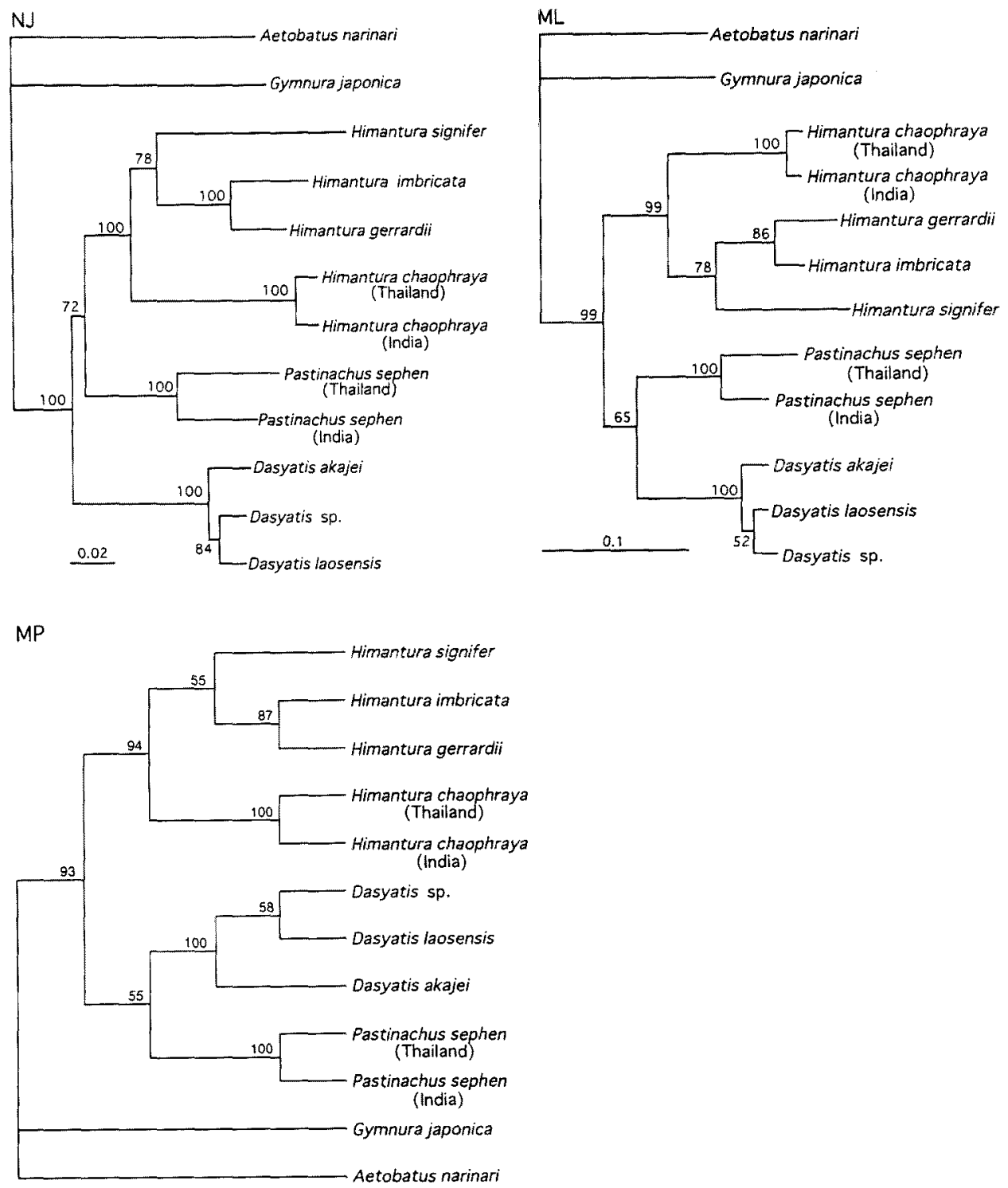

Fig. 5. Molecular phylogenetic trees according to the neighbor-joining (NJ), maximum parsimony (MP), and maximum likelihood (ML) methods for stingrays based on DNA nucleotide sequences of the cytochrome $b$ gene.

Numbers in the phylogenetic trees indicate bootstrap resampling values from 100 replicates. The bar indicates genetic distance.

sequences of eagle ray $A$. narinari and butterfiy ray $G$. japonica, were employed in order to root the molecular phylogenetic trees with the neighbor-joining, maximum parsimony, and maximum likelihood methods.

According to taxonomic grouping, ${ }^{4,19)}$ the genus Dasyatis branches with the genus Himantura, both belonging to the family Dasyatididae. In the present study on molecular phylogeny of stingrays, the genus Himantura formed one group with a high bootstrap value by the neighbor-joining, maximum parsimony, and maximum likelihood methods based on DNA nucleotide sequences. The giant stingray $H$. chaophraya collected in India, a synonym of $H$. fluviatalis, ${ }^{15,16)}$ was closely related to the same species collected in Thailand. However, the DNA nucleotide and amino acid sequences of cytochrome $b$ of $H$. chaophraya specimens collected in India and Thailand were clearly different from each other. These two races probably diverged since their geographical isolation to different river systems during evolutionary time. It is interesting to investigate their detailed morphological characterizations. In spite of such an unsettled grouping for the genus Himantura, all stingrays in this genus formed a closely related group. The present study demonstrated that $H$. gerrardii was the closest relative of $H$. imbricata, whereas $H$. signifer was closely related to $H$. imbricata and $H$. gerrardii. Such relationship is not inferred by the data reported previously based on morphological characters. ${ }^{16-19}$

The marine stingray of Dasyatis sp. is the closest relative of $D$. laosensis, the two species together forming one group in any molecular phylogenetic trees with high bootstrap values. Such a close relationship between $D$. laosensis and the marine stingray of Dasyatis sp. is interesting 

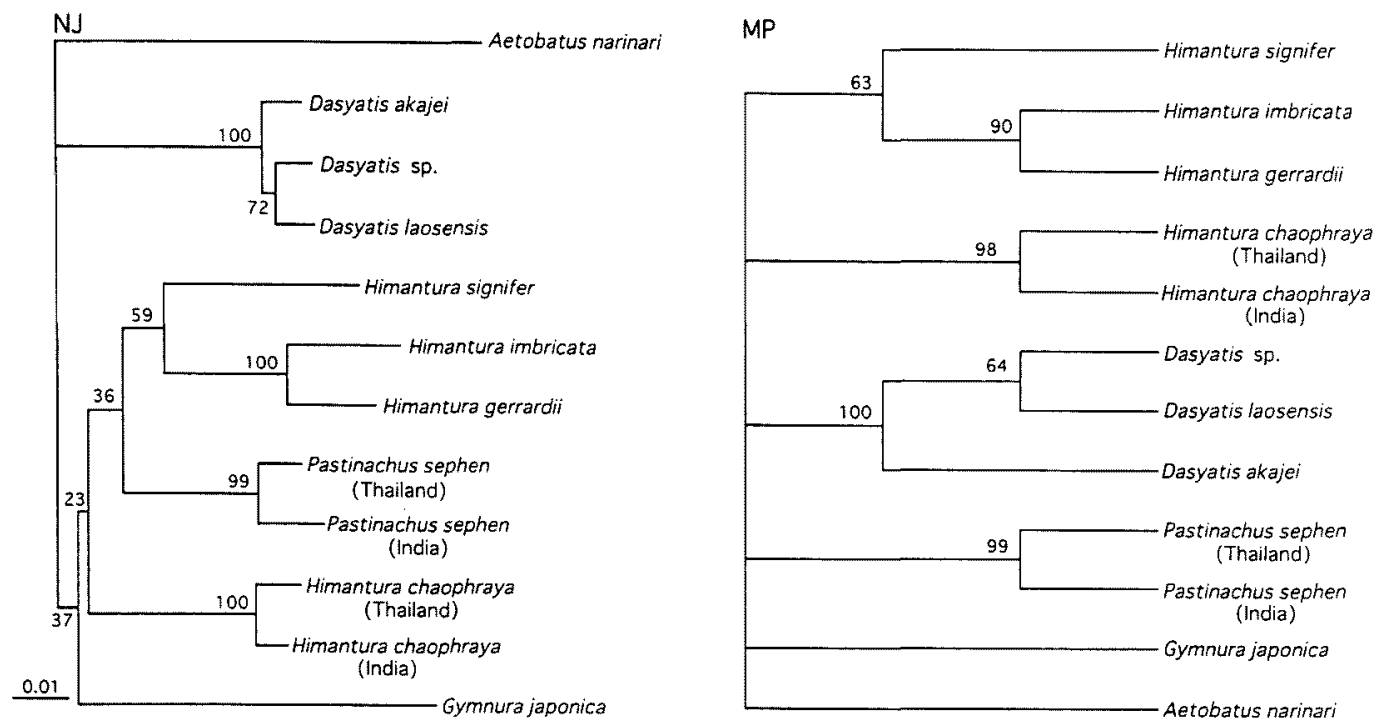

Fig. 6. Molecular phylogenetic trees according to the neighbor-joining (NJ), maximum parsimony (MP), and maximum likelihood (ML) methods for stingrays based on amino acid sequences of cytochrome $b$.

Numbers in the phylogenetic trees indicate bootstrap resampling values from 100 replicates. The bar indicates genetic distance.

from the ecological and physiological aspects as well, since D. laosensis of Laos inhabits freshwater, whereas Dasyatis sp. collected from Thailand lives in a marine habitat.

Judging from low bootstrap values, DNA nucleotide and deduced amino acid sequences data for cytochrome $b$, we find it difficult to confidently establish the phylogenetic relationship of $P$. sephen with other genera of stingray. The present phylogenetic trees constructed according to the maximum parsimony, and maximum likelihood methods suggest that it is the closest relative of the genus Dasyatis. But, the neighbor-joining method implies that it could be closely related to the genus Himantura. However their bootstrap values were both low. Bigelow and Schroeder ${ }^{20)}$ reported a brief description that Pastinachus was once classified under the subgenus Dasyatis. In this study we infer that specimens of $P$. sephen collected in In$\mathrm{dia}^{21)}$ and Thailand are slightly different from each other in their DNA nucleotide and amino acid sequences of cytochrome $b$ as in the case of $H$. chaophraya.

In conclusion, we have analyzed 12 taxa from Thailand, India, Laos, and Japan to elucidate phylogenetic links of freshwater stingrays and also their relationship with marine stingrays. The molecular phylogenetic trees derived from our analyses demonstrated some of their relations distinctly and others vaguely. The occurrence of local races in the two freshwater stingrays, $H$. chaophraya and $P$. sephen is also revealed. Further studies are required to satisfactorily correlate such differences in the same species with those in morphological characters.

\section{References}

1) K. A. Dunn and J. F. Morrissey: Molecular phylogeny of eleasmobranchs. Copeia, 1995, 526-531 (1995).

2) J. D. McEachran and K. A. Dunn: Phylogenetic analyses of skates, a morphologically conservative clade of elasmobranchs (Chondrochthyes: Rajidae). Copeia, 1998, 271-290 (1998).
3) N. R. Lovejoy: Systematics of myliobatoid elasmobranchs: with emphasis on the phylogeny and historical biogeography of neotropical freshwater stingrays (Potamotrygonidae: Rajiformes). Zool. J. Linnean Soc., 117, 207-257 (1996).

4) S. J. Nelson: Fishes of the World, 3rd edn., Wiley and Sons, New York, 1994, 600p.

5) T. D. Kocher, W. K. Thomas, A. Meyer, S. V. Edwards, S. Paabo, F. X. Villablanca, and A. C. Wilson: Dynamics of mitochondrial DNA evolution in animals. Amplification and sequencing with conserved primers. Proc. Natl. Acad. Sci. USA, 86, 6196-6200 (1989).

6) T. Kitamura, A. Takemura, S. Watabe, T. Taniuchi, and M. Shimizu: Mitochondrial DNA analysis for the cytochrome $b$ and Dloop region from the bull shark Carcharhinus leucas. Fisheries Sci., 62, 21-27 (1996).

7) T. Kitamura, A. Takemura, S. Watabe, T. Taniuchi, and M Shimizu: Molecular phylogeny of the sharks and rays of superorder Squalea based on mitochondrial cytochrome $b$ gene. Fisheries Sci, 62, 340-343 (1996).

8) S. Palumbi, A. Martin, S. Romano, W. O. McMillian, L. Stice, and G. Grabowski: The Simple Fool's Guide to PCR, Ver. 2, Department of Zoology, Univ. Hawaii, Honolulu, 1991.

9) N. Saitou and M. Nei: The neighbor-joing method: a new method for reconstructing phylogenetic trees. Mol. Biol. Evol., 4, 406-425 (1987).

10) M. O. Dayhoff, R. M. Schwartz, and B. C. Orcutt: A model of evolutionary change in proteins, in "Atlas of Protein Sequence and Structure, Vol. 5, Suppl. 3' (ed. by M. O. Dayhoff), National Biomedical Research Foundation, Washington, D.C., 1978, pp. 345-352.

11) J. Felsenstein: Evolutionary trees from DNA sequences: a maximum likelihood approach. J. Mol. Evol., 17, 368-376 (1981).

12) J. Felsenstein: PHYLIP (Phylogeny Inference Package), Ver. 3.5c, Department of Genetics, Univ. Washington, Seattle, 1995.

13) W. P. Maddison and D. R. Maddison: MacClade: Analysis of Phylogeny and Character Evolution, Ver. 3, Sinauer Associates, Sunderland, 1992, 404p.

14) D. L. Sowofford: PAUP: Phylogenetic Analysis Using Parsimony, Ver. 3.1.1, Illinois Natural History Survey, Champaign, 1993.

15) L. J. V. Compagno and S. F. Cook: The exploitation and conservation of freshwater elasmobranchs: status of taxa and prospects for the future. J. Aquaricult. Aquat. Sci., 7, 62-90 (1995).

16) L. J. V. Compagno and T. R. Roberts: Freshwater stingrays 
(Dasyatidae) of Southeast Asia and New Guinea, with description of a new species of Himantura and reports of unidentified species. Environ. Biol. Fishes, 7, 321-339 (1982).

17) T. R. Roberts and J. Karnasuta: Dosyatis laosensis, a new whiptailed stingray (family Dasyatididae), from the Mekong River of Laos and Thailand. Environ. Biol. Fishes, 20, 161-167 (1987).

18) S. Monkolprasit and T. R. Roberts: Himantura chaophraya, a new giant freshwater stingray from Thailand. Jpn. J. Ichthyol., 37, 203$208(1990)$.
19) K. Nishida: Phylogeny of the suborder Myliobatidoidei. Mem. Fac. Fish., Hokkaido Univ., 37, 1-108 (1990).

20) H. B. Bigelow and W. C. Schroeder: Sawfishes, guitarfishes, skates and rays. Mem. Sears Found. Mar. Res., 1, 1-514 (1953).

21) M. P. Srivastava: On the occurrence of the stingray, Dasyatis (Pastinachus) sephen (Forsk.) Rajiformes, Dasyatididae in freshwater rivers of northeastern Bihar. J. Freshwater Biol., 3, 281285 (1991). 